This item was submitted to Loughborough's Research Repository by the author.

Items in Figshare are protected by copyright, with all rights reserved, unless otherwise indicated.

\title{
Atomistic-scale modelling of nanoindentation into optical coatings
}

PLEASE CITE THE PUBLISHED VERSION

http://dx.doi.org/10.1080/14786430903321412

PUBLISHER

(C) Taylor \& Francis

VERSION

AM (Accepted Manuscript)

LICENCE

CC BY-NC-ND 4.0

REPOSITORY RECORD

Gheewala, Ismail, Steven D. Kenny, and Roger Smith. 2019. "Atomistic-scale Modelling of Nanoindentation into Optical Coatings”. figshare. https://hdl.handle.net/2134/11628. 
This item was submitted to Loughborough's Institutional Repository (https://dspace.lboro.ac.uk/) by the author and is made available under the following Creative Commons Licence conditions.

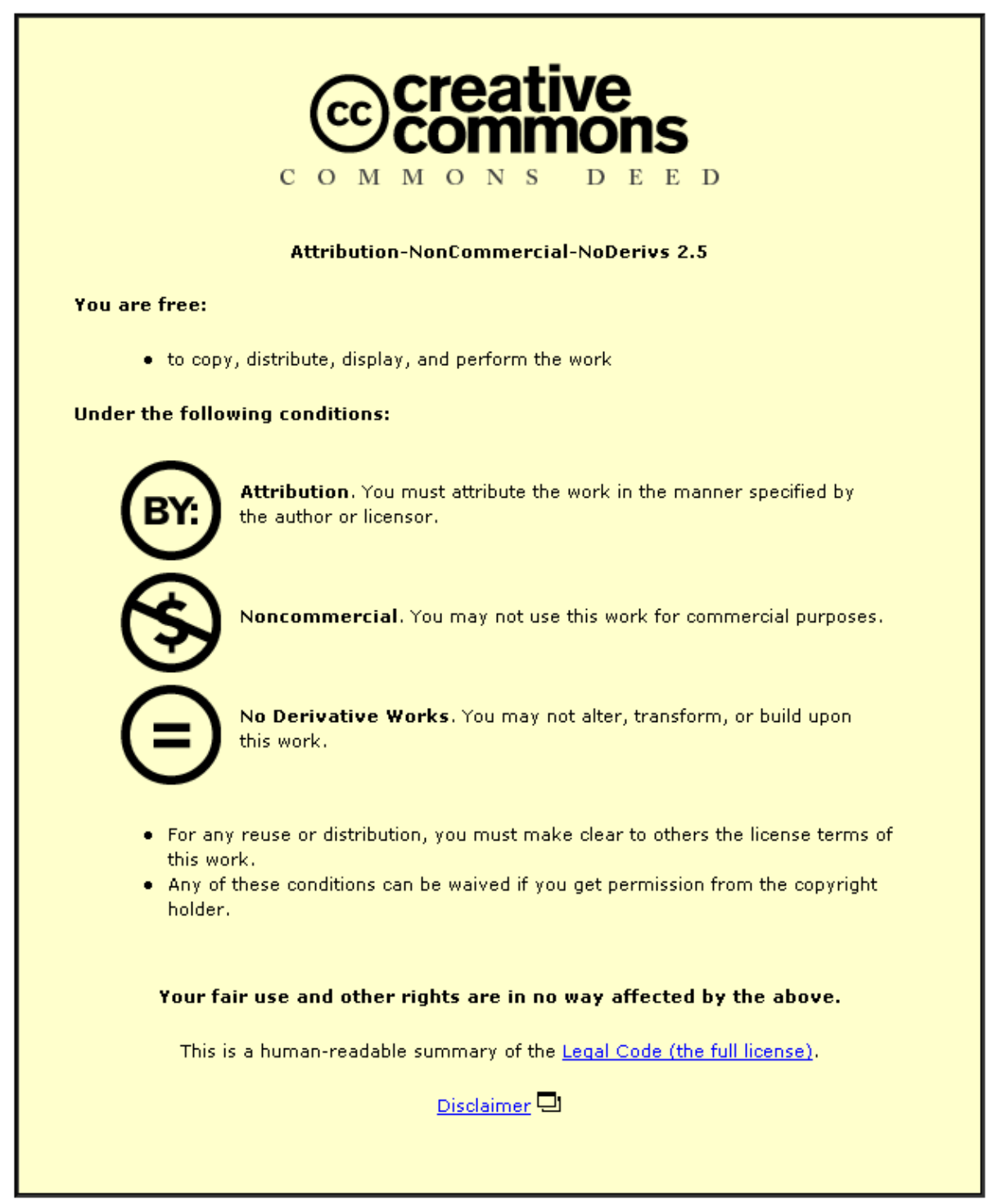

For the full text of this licence, please go to: http://creativecommons.org/licenses/by-nc-nd/2.5/ 


\title{
RESEARCH ARTICLE
}

\section{Atomistic Scale Modelling of Nanoindentation into Optical Coatings}

\author{
I. Gheewala ${ }^{a}$, S. D. Kenny ${ }^{\text {a } *}$ and R. Smith ${ }^{\mathrm{a}}$ \\ a Department of Mathematical Sciences, Loughborough University, Loughborough, \\ Leicestershire LE11 3TU, United Kingdom \\ (Received 00 Month 200x; final version received 00 Month 200x)
}

\begin{abstract}
Simulations of nanoindentation into a typical optical coatings stack employed in energy efficient glazing have been performed using classical molecular dynamics (MD) and a coupled finite element/MD methodology. The coatings stack consists of a low emissivity material, Ag, sandwiched between two layers of a transparent conducting oxide (TCO), ZnO. Simulations into both the $\mathrm{ZnO}$ and the coatings stack show a strong interaction between the tip symmetry and crystal symmetry in the observed displacement field. A large amount of elastic recovery is observed for both the $\mathrm{ZnO}$ system and the coatings stack, but with an impression left on the surface that looks like a crack but extends no further than the tip imprint at maximum depth. The full stack is observed to have a lower hardness once there is a significant penetration of the displacement field into the $\mathrm{Ag}$, when compared to the pure $\mathrm{ZnO}$ system. A comparison between the coupled finite element/MD methodology and the fixed boundary MD only model shows that the boundary conditions have little influence on the calculated results.
\end{abstract}

\section{Introduction}

Understanding hardness at the nanoscale is of increasing importance, as not only does it allow the study of the underlying atomistic mechanisms of contact, but it also allows the properties of thin coatings and nanostructured materials to be probed. Nanostructured materials often exhibit unique mechanical properties [1]. This combined with the large advances in techniques for processing nanocrystalline materials has led to an increase in the study of these materials. Furthermore, the discovery of effects such as the inverse Hall-Petch phenomena [2] has made studying these systems interesting both from a fundamental science and an engineering point of view. Thin coatings are another example of a nanoscale material that has become increasingly important with a huge variety of uses. As well as their more traditional application such as hard coatings they are increasingly important in areas such as solar cells and energy efficient glazing. The mechanical properties of these optical coatings are often found to be very important as they frequently represent their main failure mechanism.

Conventional methodologies for measuring hardness are not applicable at the nanoscale and it was only with the advent of scanning probe techniques [3] that such measurements were possible. These techniques enabled the nanoindentation methodology [4-6] to be developed, which is the experimental technique of choice for probing a material's mechanical properties at the nanoscale. The technique measures the force exerted on the tip as a function of the indentation depth and thus far more information is available than from a conventional hardness test. Furthermore the indentation can be characterised post indentation by utilising

\footnotetext{
* Corresponding author. Email: S.D.Kenny@lboro.ac.uk
} 


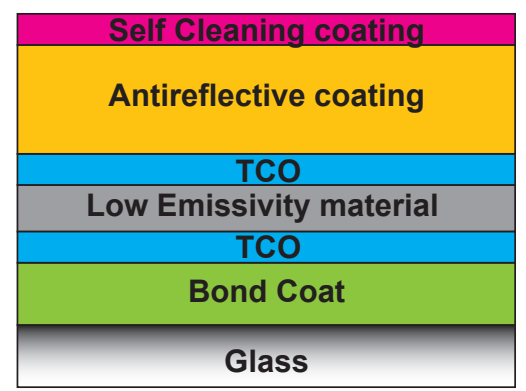

Figure 1. A typical coatings stack for an energy efficient glazing.

the indentation tip as a probe. Thus nanoindentation experiments can offer far more information than the hardness of the material. Interpreting the results of nanoindentation measurements can also be very complicated, especially when the material is a thin film or consists of thin layers.

Modelling has played a significant role in interpreting the results of nanoindentation experiments due to the fact that the size scales involved are accessible to atomistic scale modelling. Initial work in the field concentrated on the physics of contact employing small system sizes to study the initial stages of the contact of a tip with a surface using classical MD [7, 8] and ab-initio MD [9]. Large scale MD work has highlighted the link between the emission of dislocations in metals and the "pop-ins" that are observed experimentally [10-12]. Furthermore the interaction between the tip and crystal symmetry and the dislocation mechanisms present in both fcc and bcc materials has been studied $[11,13]$.

This work is focussed on modelling a thin film stack that is common in energy efficient glazings, a typical coatings stack is shown in fig. 1. We have concentrated on the part of the stack containing the low emissivity materials sandwiched between two layers of a transparent conducting oxide (TCO). In this work we have modelled this system by simulating a layer of $\mathrm{Ag}$ sandwiched between two layers of $\mathrm{ZnO}$, which are typical materials for the low emissivity layer and the TCO respectively. The mechanical behaviour of this part of the coatings stack is thought to be important in determining the overall response of the thin film stack [14]. This system is studied by modelling nanoindentation of $\mathrm{ZnO}$, a $\mathrm{Ag} / \mathrm{ZnO}$ system, a $\mathrm{ZnO} / \mathrm{Ag}$ system and finally the complete $\mathrm{ZnO} / \mathrm{Ag} / \mathrm{ZnO}$ thin film. This allows the upper and lower interface of the system to be examined separately before investigating the full system. It also allows all the results to be compared to a pure $\mathrm{ZnO}$ system.

\section{Methodology}

The nanoindentation process has been modelled by MD employing an atomistic substrate and tip, with the tip connected to springs [15], in order to mimic an AFM cantilever. Fixed boundary conditions have been applied to all surfaces of the substrate, barring the surface being indented, and to the top of the indenter, see fig. 2. The presence of the fixed boundary conditions can cause artificial effects [16], but periodic boundary conditions also suffer from issues [17]. Some simulations have been performed using a coupled finite-element (FE) method-MD methodology [18] in which the MD region was embedded in a large scale continuum region, but it has not yet been possible to use this for simulations containing multilayers. Integration was performed using the velocity-Verlet algorithm [19] with a time step of 1 fs. The simulations were performed at $300 \mathrm{~K}$, with a Berendsen thermostat [20] first applied to all except the fixed atoms to heat the system up. For the MD only 


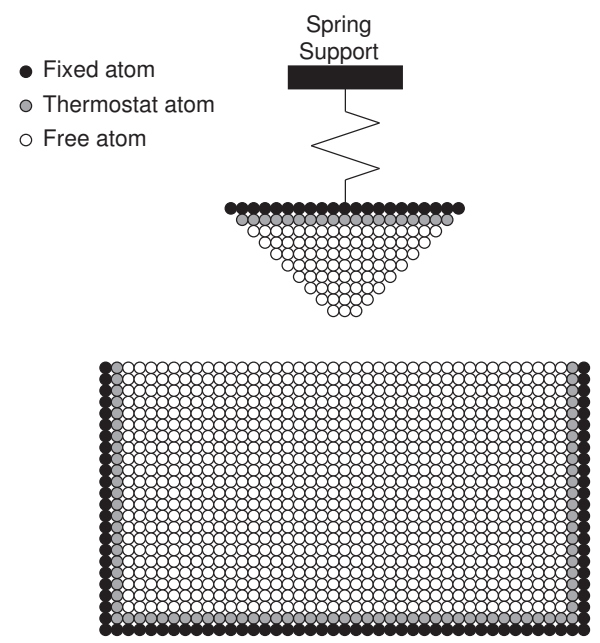

Figure 2. A schematic of the model used to simulate the nanoindentation process.

simulations the temperature was controlled during the indentation by applying the Berendsen thermostat [20] to the atomic layers just inside of those held fixed. For the coupled model it was not necessary to use a thermostat as the work done on the system causes only a negligible heating effect, due to the effective system size.

The indentation process was modelled by moving the spring support (see fig. 2) down towards the surface at a speed of $10 \mathrm{~m} / \mathrm{s}$. Indentations at this speed have been shown to cause only minimal local heating in the sample and thus provide an acceptable model of the experiments. The tip was moved so as to be up to 6 $\mathrm{nm}$ into the surface; it was then held for up to 50 ps before being retracted from the surface, at the same speed as during indentation. The tip was retracted until the force between the tip and the substrate was zero. The system for the full stack consisted of 482,112 $\mathrm{Ag}$ atoms sandwiched between $361,584 \mathrm{ZnO}$ units on both the top and the bottom, with the surface dimensions being $30 \mathrm{~nm} \times 30 \mathrm{~nm}$. For the pure $\mathrm{ZnO}$ thin film, a system of dimensions $23 \mathrm{~nm} \times 23 \mathrm{~nm} \times 23 \mathrm{~nm}$ was used, which consisted of 1.05 million atoms. For the coupled model this was connected to a FE region consisting of 226,000 nodes forming 1.3 million elements. The FE mesh was constructed so that the mesh was fine close to the atomistic region and coarsened towards the edges. The combined FE-MD region had dimensions of 150 $\mathrm{nm} \times 73 \mathrm{~nm} \times 150 \mathrm{~nm}$ and was equivalent to over 140 million atoms. The tip was modelled using a diamond cube corner indenter, whose faces are the $\{100\}$ surfaces and with the (111) plane orientated parallel to the indentation surface.

Interactions between the atoms in the indenter were modelled using the manybody Brenner potential [21,22] and the tip-surface interactions were modelled by the purely repulsive ZBL potential [23]. The Ag atoms were modelled using an Ackland [24] form of the Finnis-Sinclair potential [25]. The interactions between the $\mathrm{Zn}$ and $\mathrm{O}$ atoms were modelled using the many-body potential of Erhart et al. [26], we investigated modelling this with a fixed charge model but this was found to be unstable for the polar surface. Interactions between the $\mathrm{ZnO}$ and $\mathrm{Ag}$ layers were fitted to the ab-initio results of Lin and Bristowe [27] using a Morse potential [28] for the nearest neighbour $\mathrm{Ag}$ and $\mathrm{O}$ interactions and a repulsive ZBL potential between the $\mathrm{Ag}$ and $\mathrm{Zn}$ atoms. The $\mathrm{Ag}-\mathrm{Zn}$ potential was cutoff such that it was not active at the equilibrium distance and different Ag-O Morse potentials were fitted for the upper and lower interface. Fitting was performed so that the work of separation (the energy difference between the bonded interface and the two free surfaces) and separation distance between the $\mathrm{ZnO}$ and $\mathrm{Ag}$ layers was in good agreement with the ab-initio calculations, the potential parameters for are 


\begin{tabular}{|c|c|c|}
\hline $\begin{array}{c}\text { Morse } \\
\text { Parameters }\end{array}$ & $\begin{array}{c}\text { Lower Ag-O } \\
\text { interface }\end{array}$ & $\begin{array}{c}\text { Upper Ag-O } \\
\text { interface }\end{array}$ \\
\hline $\mathrm{D}_{0}(\mathrm{eV})$ & 0.333 & 0.756 \\
\hline $\mathrm{r}_{0} \AA$ & 2.590 & 2.549 \\
\hline $\mathrm{S}$ & 1.057 & 1.307 \\
\hline$\beta$ & 1.618 & 1.671 \\
\hline
\end{tabular}

Table 1. The parameters for the modified Morse potential for the upper and lower Ag-O interface.

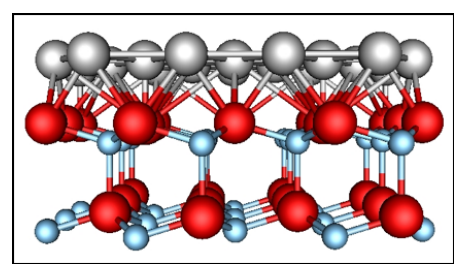

(a)

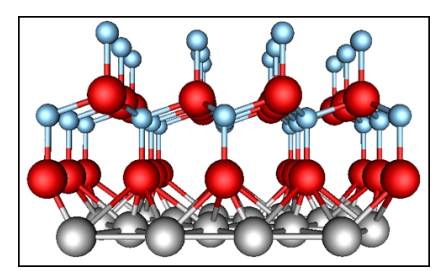

(b)

Figure 3. The structures of the (a) lower and (b) upper interface as viewed from the side. The red spheres represent oxygen atoms, the blue ones zinc atoms and the grey ones silver atoms.

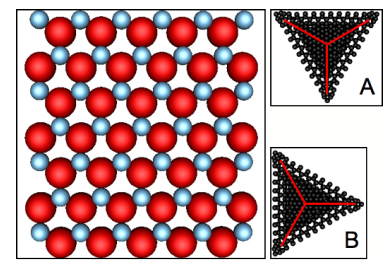

Figure 4. The (0001) ZnO surface and its relationship to the two indenter orientations, A and B, employed in the simulations.

given in table 2. Different potentials are needed for the two interfaces as the Morse potential is unable to account for the different coordination at the two interfaces. Given the limited data with which to fit to fitting a more sophisticated potential than the Morse one was not attempted.

In this work we have modelled this coatings stack by simulating a $8.4 \mathrm{~nm}$ thick layer of $\mathrm{Ag}$ sandwiched between two $9.3 \mathrm{~nm}$ thick layers of $\mathrm{ZnO}$. We have modelled nanoindentation of $\mathrm{ZnO}$, a $\mathrm{Ag} / \mathrm{ZnO}$ system, a $\mathrm{ZnO} / \mathrm{Ag}$ system and finally the complete $\mathrm{ZnO} / \mathrm{Ag} / \mathrm{ZnO}$ thin film. The lower interface, see fig. 3(a), in our model consists of the oxygen terminated $(2 \times \sqrt{3}) \mathrm{ZnO}(0001) / \mathrm{Ag}$ (111) interface with $[110]_{\mathrm{Ag}} \|[1 \overline{1} 00]_{\mathrm{ZnO}}$ and the structure corresponds to fig $5(\mathrm{a})$ in ref. [27]. The upper interface, see fig. $3(\mathrm{~b})$, is also $(2 \times \sqrt{3}) \mathrm{Ag}(111) / \mathrm{ZnO}(0001)$ interface with $[110]_{\mathrm{Ag}} \|[1 \overline{1} 00]_{\mathrm{ZnO}}$ but with onefold $\mathrm{ZnO}-\mathrm{Ag}$ bonding at the interface as proposed in the work of Phillips and Bristowe [29]. Using the lattice constants from the empirical potentials employed in this study this gives a $3.7 \%$ compression laterally in the $\mathrm{Ag}$ layer.

A number of the simulations have been performed with two different orientations of the tip relative to the $\mathrm{ZnO}$ (0001) surface. These are shown in fig. 4 and henceforth are referred to as orientation $\mathrm{A}$ and $\mathrm{B}$. In orientation $\mathrm{A}$ the edge of the indenter is aligned in the $[1 \overline{1} 00]_{\mathrm{ZnO}}$ direction, whilst for orientation $\mathrm{B}$ the face of the indenter is aligned in the $[1 \overline{1} 00]_{\mathrm{ZnO}}$ direction.

Calculating the contact pressure during the simulation is the modelling equivalent of the experimental procedure for calculating hardness. This is performed in all of the simulations by dividing the normal force on the tip in the simulations by the actual contact area of the tip with the substrate in the simulations. Tip-substrate contact areas are measured from images of the indentation so that both the surface bending and tip compression can be taken into account. The Young's modulus is 


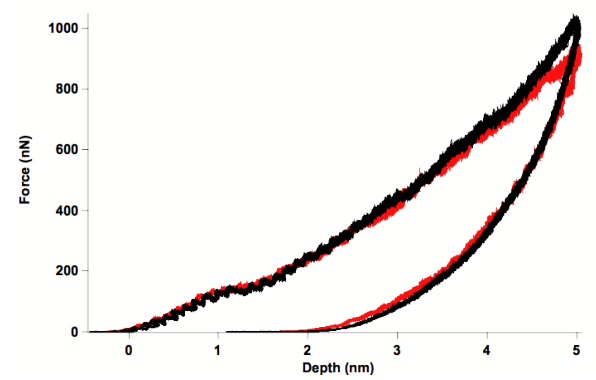

Figure 5. The force-depth curve for the nanoindentation of the $\mathrm{ZnO}$ system, the black curve is the MD only model, whilst the red curve is the FE-MD model.

calculated in the way proposed by Oliver and Pharr [6] by fitting a straight line to the initial unloading part of the curve to calculate the variation of the pressure with the indentation depth.

\section{Results}

The simulations of $\mathrm{ZnO}$ use a cube of material with sides of $23 \mathrm{~nm}$ and a tip with a tip radius of $2.5 \mathrm{~nm}$, both $\mathrm{A}$ and $\mathrm{B}$ orientations of the tip have been considered. A FE-MD simulation of this system has also been performed with the tip in orientation B. This helps to gauge the effect of the fixed boundary conditions on the simulations. The force-depth curve from the MD only model and the FE-MD model can be seen in fig. 5, which shows that the two curves are very similar, indicating that the boundary conditions are having very little influence on the simulations. There is a slight difference in the force at peak indentation depth with the maximum force in the coupled model being $950 \mathrm{nN}$, whereas in the MD only model it is $1025 \mathrm{nN}$. There is also slightly more elastic recovery in the FE-MD model than for the case of the MD only model. The contact pressure and Young's modulus for the simulations are given in table 2. As can be seen these results are practically identical for both models and in fact for both indenter orientations. The experimentally measured nanohardnesses for $\mathrm{ZnO}$ vary quite widely depending on the indentation depths and particularly on the mechanism used for growing the $\mathrm{ZnO}[30-32]$. The results in this work agree well with the larger values found in the literature. Differences between the two models can be seen when looking at the numbers of displaced atoms around the tip at peak and post indentation. At peak indentation depth almost $40 \%$ more atoms are seen to be displaced by $>5 \AA$ in the coupled model compared to the MD only model, due to the less restrictive boundary conditions. After the tip has been retracted there are $25 \%$ less atoms displaced by $>5 \AA$ in the coupled model compared to the MD only model, which illustrates the greater elastic recovery observed for the coupled model. After the indentations in both models an impression of the tip is left in the surface, which closes up due to the elastic recovery but fails to fully close thus leaving a crack like feature on the surface. No slip is seen in the $\mathrm{ZnO}$ during the indentation in either model, the plastically damaged material left after the indentation appears to be in an amorphous state.

The lower interface was modelled by relaxing the system with a $3 \AA$ layer along the sides and bottom of the substrate held fixed for $10 \mathrm{ps}$, before applying the Berendsen thermostat to all barring the fixed atoms, in order to heat the system up to $300 \mathrm{~K}$ for a period of $5 \mathrm{ps}$. The thermostat was then applied to a $8 \AA$ thick layer next to the fixed atoms and the simulation proceeded for a further 10 ps. These boundary conditions are the same as employed during the indentation 


\begin{tabular}{|c|c|c|c|}
\hline $\begin{array}{c}\text { Simulation } \\
\text { (Orientation) }\end{array}$ & $\begin{array}{c}\text { Indentation } \\
\text { depth }(\mathrm{nm})\end{array}$ & $\begin{array}{c}\text { Contact } \\
\text { pressure }(\mathrm{GPa})\end{array}$ & $\begin{array}{c}\text { Young's } \\
\text { modulus }(\mathrm{GPa})\end{array}$ \\
\hline ZnO (A) & 5.0 & 12.7 & 110 \\
\hline ZnO (B) & 5.0 & 12.6 & 111 \\
\hline ZnO Fe-MD (B) & 5.0 & 12.6 & 111 \\
\hline Upper Interface & 1.2 & 12.9 & 92 \\
\cline { 2 - 4 }$(\mathrm{A})$ & 1.8 & 12.3 & 101 \\
\cline { 2 - 4 } & 2.4 & 12.5 & 102 \\
\cline { 2 - 4 } & 3.0 & 11.8 & 105 \\
\hline \multirow{2}{*}{$\begin{array}{c}\text { Full stack } \\
\text { (A) }\end{array}$} & 3.0 & 11.2 & 87 \\
\cline { 2 - 4 } & 4.0 & 11.2 & 96 \\
\cline { 2 - 4 } & 5.0 & 11.0 & 95 \\
\hline \multirow{2}{*}{$\begin{array}{c}\text { Full stack } \\
\text { (B) }\end{array}$} & 5.0 & 11.8 & 99 \\
\cline { 2 - 4 } & 5.0 & 11.4 & 96 \\
\hline
\end{tabular}

Table 2. The calculated contact pressures and Young's moduli for the different systems considered as a function of the indentation depth. The orientation refers to the indenter orientation as discussed in the methodology.

stage. During both the relaxation and the heating phases little change was observed with the system. On starting the indentation into the surface a number of slip systems are immediately activated, with dislocations gliding out to interact with the boundary conditions within about $80 \mathrm{ps}$. This is due to the fact that the Ag that is being indented is under compression and thus the critical stress is exceeded very early on in the indentation simulation. Due to the fact that there is such a strong interaction with the boundary conditions the results from this simulation are of limited value.

The upper interface was relaxed for 15 ps with periodic boundary conditions with just the bottom layer held fixed, this allowed the height of the substrate to relax. During this phase of the simulation there was a contraction of the $\mathrm{ZnO}$ layer, simulations without this stage in them showed large oscillations in the $\mathrm{ZnO}$ layer upon heating. The system was then relaxed with a $3 \AA$ layer along the sides and bottom of the substrate held fixed for $10 \mathrm{ps}$, before applying the Berendsen thermostat to all barring the fixed atoms in order to heat the system up to $300 \mathrm{~K}$ for a period of $5 \mathrm{ps}$. The system was then held at $300 \mathrm{~K}$ by applying the Berendsen thermostat to a $8 A$ layer of atoms around the outside for $155 \mathrm{ps}$, by which time the slip systems in the coatings stack were stable. Upon heating the system to $300 \mathrm{~K}$ slip systems within the Ag immediately became active, no slip was seen during the relaxation phase. The activation of the slip systems allowed for considerable strain relief to take place in the compressed $\mathrm{Ag}$ layer before the nanoindentation modelling commenced. On indenting into the $\mathrm{ZnO}$ layer the system behaviour was very similar to that observed when the $\mathrm{ZnO}$ system was indented. The force-displacement curve to a depth of $2.4 \mathrm{~nm}$ for this system along with an equivalent $\mathrm{ZnO}$ only system is shown in fig. 6 . The force at the slightly larger peak indentation depth of $3 \mathrm{~nm}$ was just over $400 \mathrm{nN}$, the elastic recovery was similar to that observed for the pure $\mathrm{ZnO}$ system.

The system consisting of the $\mathrm{Ag}$ layer sandwiched between two $\mathrm{ZnO}$ layers was prepared in exactly the same way as the upper interface, the only difference being that the system was held at $300 \mathrm{~K}$ for 185 ps in order to stabilise the slip systems. Due to the deeper indentation depths explored in these simulations a slightly larger tip was employed, which had a tip radius of $3 \mathrm{~nm}$. The force-depth curves for this system can be seen in fig. 7 and show that the peak force is $1400 \mathrm{nN}$ at an indentation depth of $6 \mathrm{~nm}$. A large amount of elastic recovery is observed in all the 


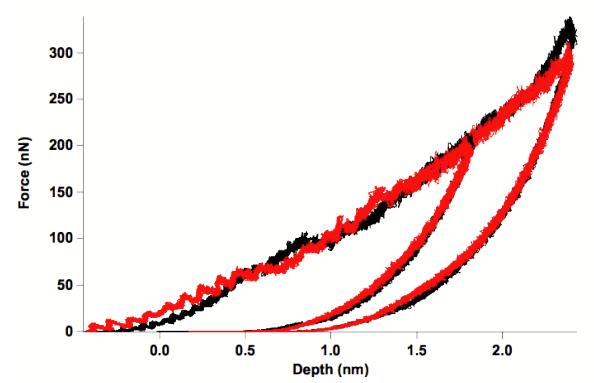

Figure 6. The force depth curve for the indentation of the upper interface (red curve) compared to the force depth curve for the $\mathrm{ZnO}$ only system.

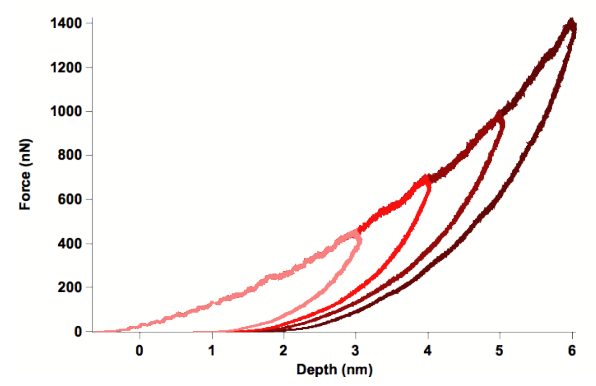

Figure 7. The force-depth curve for the full stack, consisting of a Ag layer sandwiched between two $\mathrm{ZnO}$ layers. The curves show a peak force of $1400 \mathrm{nN}$ at a depth of $6 \mathrm{~nm}$ and considerable elastic recovery on retraction of the tip. The curves represent indents of $3,4,5$ and $6 \mathrm{~nm}$ into the surface.

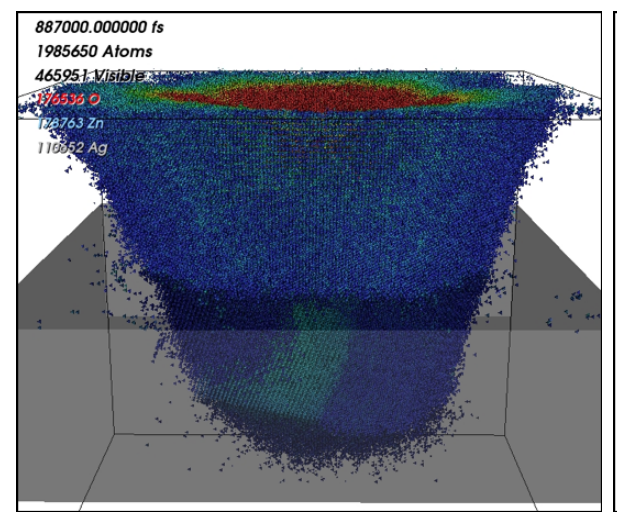

(a)

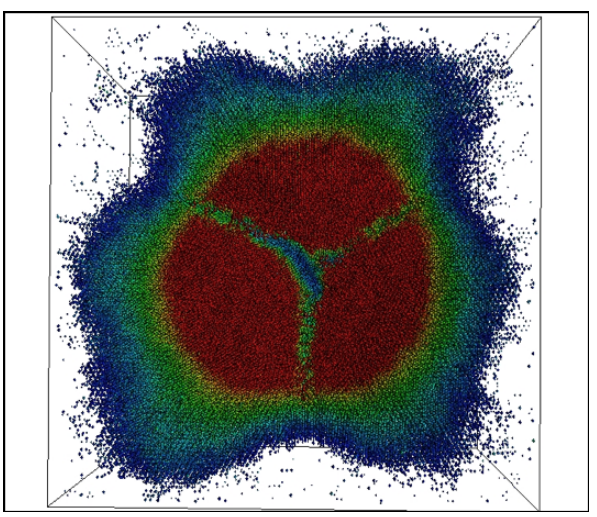

(b)

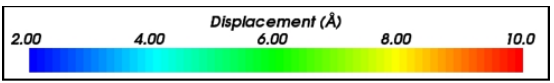

Figure 8. The displacement field in the full stack at the maximum indentation depth of $6 \mathrm{~nm}$, (a) shows the view from the side, whilst (b) is looking directly down on the surface. The grey box represents the extent of the Ag layer.

indentations, with the deeper indents recovering to a similar degree to the shallower indents. The displacement fields in the indentations of the full stack show a very strong interaction of the tip symmetry with the underlying symmetry of the $\mathrm{ZnO}$, see fig. 8. There is a large amount of displacement in the Ag layer, the majority of this being elastic but a small number of additional slip systems are activated. One of these can be seen on the left hand side of fig. 8 (a). Towards the end of the deeper indents the displacement field is seen to penetrate the lower $\mathrm{ZnO}$ layer.

The crack like features observed during the indentation of the $\mathrm{ZnO}$ system are also observed when the upper interface and the full stack are indented. In all cases the features are the result of an extensive elastic recovery of the material but with residual plastic damage, in particular along the lines of the edges of the indenter. 


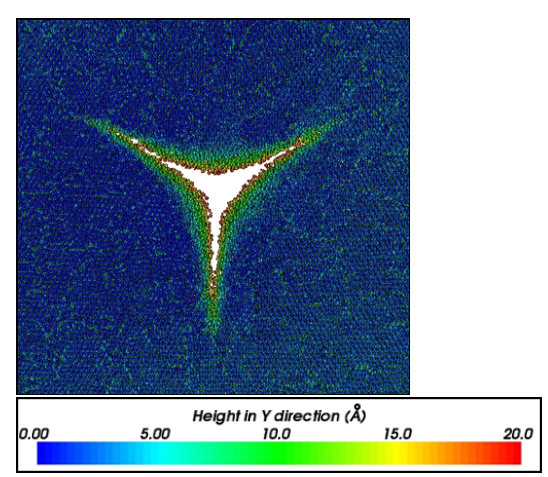

Figure 9. The surface impression left after the $6 \mathrm{~nm}$ indentation into the full coatings stack.

In all of the systems studied these features extend only as far as the impression left by the indenter edges at maximum indentation depth, thus they are not a sign of cracking occurring in the material. Fig. 9 shows these features post the $6 \mathrm{~nm}$ indentation into the full stack. The figure has been coloured on height with larger values referring to deeper into the surface. These may be due to the fact that the edges of the indenter are sharper than an experimental indenter, however, such features have been experimentally observed.

\section{Conclusions}

The contact pressures and Young's moduli for the different systems are given in table 2. It can be seen from these that the results for the shallower indents into the upper interface system give results which are very similar to those that are observed for $\mathrm{ZnO}$. When an indentation depth of $3 \mathrm{~nm}$ is reached, however, the hardness appears to be lower. This trend is also visible in the indents of the full stack, which start at $3 \mathrm{~nm}$ and show a reduced hardness. This would imply that this is a result of the softer Ag layer becoming sampled during these indents. This conclusion is supported by the large amount of displacement observed in the $\mathrm{Ag}$ layer as shown in fig. 8. At the $6 \mathrm{~nm}$ indentation depths the hardness is observed to rise again to become similar to that observed for the pure $\mathrm{ZnO}$ system. This can be attributed to one of two effects; either it is due to the fact that the lower $\mathrm{ZnO}$ layer is now showing a considerable displacement or it could be due to the fixed boundary conditions. The calculated Young's moduli for the systems containing interfaces lie somewhere between the experimental values for $\mathrm{Ag}$ and $\mathrm{ZnO}$ and show little variation with indentation depth.

Experiments and finite element modelling (FEM) of the $\mathrm{ZnO}$ and $\mathrm{Ag}$ coatings stack $[33,34]$ have shown evidence of delamination at the $\mathrm{Ag}$ - $\mathrm{ZnO}$ interface during indentation. No evidence of this is observed in these simulations, but at the deeper indentation depths slip in the Ag layers is observed, fig. 8. The lack of delamination in our models may well be due to the influence of three separate issues; firstly our indentation depths are still very small when compared to the experiments; secondly we see considerable stress relief in the Ag during the heating phase of our simulations and finally our empirical potential describing the $\mathrm{Ag}-\mathrm{ZnO}$ interface is very simple. The residual stress in the Ag layer is very important as was seen in our attempts at modelling the lower interface, with a greater residual stress leading to an earlier activation of slip systems. The amount of plastic flow in these simulations is also critical as the FEM work indicates that delamination occurs due to the $\mathrm{Ag}$ flowing laterally, leading to a tensile force at the upper $\mathrm{Ag}-\mathrm{ZnO}$ interface.

The simulations indicate that the residual stress state of thin films is of 
paramount importance when considering the mechanical properties of thin film stacks. Our attempts at modelling the lower interface illustrate that if the Ag layer is held in compression then slip systems are readily activated. The complexities of interpreting nanoindentation data from the indentation of multi-layer films is also illustrated, with the hardness varying as a function of indentation depth, due to a dependence on which parts of the film are being sampled by the strain field due to the tip.

\section{Acknowledgements}

The simulations presented in this work have been performed on the resources of Loughborough University's high performance computing centre. This work was funded by EPSRC grant no. EP/C524322/1. We acknowledge Steve Bull, Victoria Chen, Paul Warren and John Ridealgh for useful discussions and Charlotte Phillips, Zheshuai Lin and Paul Bristowe for supplying details of optimised interfaces between $\mathrm{ZnO}$ and $\mathrm{Ag}$.

\section{References}

[1] H. Gleiter, Progress in Materials Science 33 (1989) p.223-315.

[2] A.H. Chokshi, A. Rosen, J. Karch and H. Gleiter, Scripta Metall Mater 23 (1989) p.1679-1683.

[3] G. Binning, C.F. Quate and C. Gerber, Phys. Rev. Lett. 56 (1986) p.930-933.

[4] J.B. Pethica, R. Hutchings and W.C. Oliver, Philos Mag A 48 (1983) p.593-606.

[5] J.B. Pethica and W.C. Oliver, Phys Scripta T19A (1987) p.61-66.

[6] W.C. Oliver and G.M. Pharr, J Mater Res 7 (1992) p.1564-1583.

[7] U. Landman, W.D. Luedtke, N.A. Burnham and R.J. Colton, Science 248 (1990) p.454-461.

[8] A.P. Sutton and J.B. Pethica, J Phys-Condens Mat 2 (1990) p.5317-5326.

[9] R. Perez, M.C. Payne and A.D. Simpson, Phys. Rev. Lett. 75 (1995) p.4748-4751.

[10] J. Li, K.J. Van Vliet, T. Zhu, S. Yip and S. Suresh, Nature 418 (2002) p.307-310.

[11] R. Smith, D. Christopher, S.D. Kenny, A. Richter and B. Wolf, Phys. Rev. B 67 (2003) p.245405.

[12] K.J. Van Vliet, J. Li, T. Zhu, S. Yip and S. Suresh, Phys. Rev. B 67 (2003) p.15.

[13] O.R. de la Fuente, J.A. Zimmerman, M.A. Gonzalez, J. Figuerade la , J.C. Hamilton, W.W. Pai and J.M. Rojo, Phys. Rev. Lett. 88 (2002) p.036101.

[14] K.J. Belde and S.J. Bull, J Adhes Sci Technol 22 (2008) p.121-132.

[15] J. Shimizu, H. Eda, M. Yoritsune and E. Ohmura, Nanotechnology 9 (1998) p.118-123.

[16] D. Christopher, R. Smith and A. Richter, Nanotechnology 12 (2001) p.372-383.

[17] D. Saraev and R. Miller, Acta Materialia 54 (2006) p.33-45.

[18] E. McGee, R. Smith and S.D. Kenny, Int J Mater Res 98 (2007) p.430-437.

[19] M.P. Allen and D.J. Tildesley Computer Simulation of Liquids, Oxford University Press, New York, 2000.

[20] H.J.C. Berendsen, J.P.M. Postma, W.F. Vagunsteren, A. Dinola and J.R. Haak, J Chem Phys 81 (1984) p.3684-3690.

[21] D.W. Brenner, Phys. Rev. B 42 (1990) p.9458-9471.

[22] D.W. Brenner, Phys. Rev. B 46 (1992) p.1948-1948.

[23] J. Biersack, J. Ziegler and U. Littmack The Stopping and Range of Ions in Solids, Pergamon, Oxford, 1985 .

[24] G.J. Ackland, G. Tichy, V. Vitek and M.W. Finnis, Philos Mag A 56 (1987) p.735-756.

[25] M.W. Finnis and J.E. Sinclair, Philos Mag A 50 (1984) p.45-55.

[26] P. Erhart, N. Juslin, O. Goy, K. Nordlund, R. Mueller and K. Albe, J Phys-Condens Mat 18 (2006) p.6585-6605.

[27] Z. Lin and P.D. Bristowe, Phys. Rev. B 75 (2007) p.205423.

[28] L.A. Girifalco and V.G. Weizer, Phys Rev 114 (1959) p.687-690.

[29] C.L. Phillips and P.D. Bristowe, J Mater Sci 43 (2008) p.3960-3968.

[30] S. Kucheyev, J. Bradby, J. Williams, C. Jagadish and M. Swain, Appl Phys Lett 80 (2002) p.956-958.

31] T.H. Fang, W.J. Chang and C.M. Lin, Mat Sci Eng A-Struct 452 (2007) p.715-720.

[32] J. Chen and S.J. Bull, J Phys D Appl Phys 41 (2008) p.074009.

[33] J. Chen and S.J. Bull, J Phys D Appl Phys 40 (2007) p.5401-5417.

[34] J. Chen and S.J. Bull, Thin Solid Films 516 (2007) p.128-135. 